\title{
Expression analysis of heat shock protein 90 (HSP90) and Her2 in colon carcinoma
}

\author{
Enken Drecoll • Ulrich Nitsche • Karina Bauer • \\ Sabina Berezowska $\cdot$ Julia Slotta-Huspenina • \\ Robert Rosenberg $\cdot$ Rupert Langer
}

Accepted: 2 April 2014 / Published online: 15 April 2014

(C) Springer-Verlag Berlin Heidelberg 2014

\begin{abstract}
Purpose The molecular chaperone heat shock protein 90 (HSP90) plays an important role in several types of tumors also participating in the modulation of the activity of receptor tyrosine kinases activity such as members of the Her family. We evaluated the significance of HSP90 and Her2 expression in colon cancer.

Methods HSP90 and Her2 expression was determined by immunohistochemistry and by fluorescence in situ hybridization (FISH) on 355 primary resected colon carcinomas. Results were correlated with pathologic features (Union for International Cancer Control (UICC) pTNM category, tumor localisation, tumor differentiation), additional molecular genetic characteristics (BRAF, KRAS mutational status, mismatch repair genes (MMR)), and survival.

Results HSP90 immunoreactivity was observed in various degrees. Fifty-one cases $(14 \%)$ were positive for Her2 (score $2+$ and $3+$ ) with $16 / 43$ cases with Her2 $2+$ staining pattern showing amplification of Her2 determined by FISH. There was a significant correlation between high HSP90 expression and Her2 overexpression $(p=0.011)$. High HSP90 expression was associated with earlier tumor stages $(p=0.019)$, absence
\end{abstract}

\author{
E. Drecoll $\cdot$ K. Bauer $\cdot$ J. Slotta-Huspenina \\ Institute of Pathology, Technische Universität München, Munich, \\ Germany \\ U. Nitsche $\cdot$ R. Rosenberg \\ Department of Surgery, Klinikum Rechts der Isar, Technische \\ Universität München, Munich, Germany \\ S. Berezowska $\cdot$ R. Langer $(\bowtie)$ \\ Institute of Pathology, University of Bern, Murtenstr. 31, 3010 Bern, \\ Switzerland \\ e-mail: rupert.langer@pathology.unibe.ch \\ R. Rosenberg \\ Department of Surgery, Kantonsspital Baden, 5404 Baden, \\ Switzerland
}

of lymph node ( $p=0.006$ ), and absence of distant metastases $(p=0.001)$. Patients with high tumoral HSP90 levels had a better survival $(p=0.032)$, but this was not independent from other prognostic relevant pathologic parameters. Her2 expression was not associated with any of the investigated histopathological, molecular, or clinical parameters.

Conclusions High HSP90 levels are reflecting lower malignant potential in colon cancer. Her 2 positivity can be observed in a small number of cases. Targeting HSP90 and/or Her2 may be an alternative therapeutic approach in colon cancer in a subset of patients.

Keywords HSP90 $\cdot$ Her2 $\cdot$ Immunohistochemistry $\cdot$ Colon cancer

\section{Introduction}

A significant number of gastric and gastroesophageal adenocarcinomas shows amplification and overexpression of Her2 $[1,2]$ leading to the introduction of anti-Her2-directed therapy with trastuzumab in the treatment of metastatic adenocarcinomas of the esophagogastric junction and the stomach $[3,4]$. In contrast to adenocarcinomas of the upper gastrointestinal tract, studies about Her2 in colorectal cancer are less comprehensive, and the studies show a high variability of Her2 positivity rates in these tumors [5-12].

Her2 has been shown to interact with HSP90, a molecular chaperone belonging to the group of heat shock proteins. These molecules are responsible for the correct folding of proteins, prevention of protein aggregation, and protein activation $[13,14]$. There are data which suggest that HSP90 expression may also support the effects of oncogenic Her2 [15] which represents a potential mechanism of resistance to Her2-directed drugs. On the other hand, HSP90 inhibitors, which have been developed recently, may potentiate the 
effects of anti-cancer drugs targeting client proteins of HSP90 [16]. The relationship between HSP90 and Her2, however, has not been investigated so far for colon carcinomas. Moreover, there are currently only scarce data about HSP90 expression in human colon cancer tissue [17, 18].

The aim of the present study was to investigate the role of Her2 in colon cancer and to get deeper insights of tumor biology and behavior regarding Her2-positive carcinomas. We furthermore investigated any possible relationship of Her2 and HSP90 as potentially targetable molecules in colon cancer.

\section{Materials and methods}

Patients and tissues

We investigated formalin-fixed and paraffin-embedded (FFPE) archival cancer tissue from 355 patients with colon carcinoma who underwent surgery between 1993 and 2005 at the Klinikum Rechts der Isar of the Technische Universität München (Germany). All patients had a primary resection. Informed consent for the use of additional molecular analysis was given at the time of surgery, and the use of archival tissue for molecular analysis was approved by the local ethical commission (No. 2136/08). Follow-up data (overall survival) were available for 349 patients.

\section{Immunohistochemistry}

Immunohistochemistry was performed on FFPE tissue on a tissue microarray (TMA) as described before [19]. Representative tumor sections were marked, and two core needle biopsy specimens of $1.0 \mathrm{~mm}$ in diameter were retrieved and placed in a recipient wax block using a manual arrayer (Beecher Instruments; Sun Prairie, Wisconsin, USA). For a subset of cases $(n=17)$, where additional lymph node metastases were investigated, full slide sections were used (see below).

The paraffin blocks were freshly cut $(3 \mu \mathrm{m})$. Slides were dewaxed and rehydrated, with subsequent heat-induced antigen retrieval using $10 \mathrm{mM}$ citrate buffer $(\mathrm{pH} \mathrm{6}), \mathrm{H}_{2} \mathrm{O}_{2}$ blocking using $3 \% \mathrm{H}_{2} \mathrm{O}_{2}$ in aqua dest., and avidin/biotin blocking (avidin/biotin blocking kit; Vector Laboratories, Inc., Burlingame, CA, USA). The sections were then incubated with antibodies for HSP90 (1:50; Abcam, Cambridge, UK), which recognizes both alpha and beta isoforms of HSP90, Her2 (1:300; DAKO, Glostrup, DK), and for MLH1, MSH6, MSH2, and PMS2 (1:200, 1:200, 1:1,600, and 1:75, respectively; all Leica Novocastra). Immunodetection was performed with the Dako REAL ${ }^{\mathrm{TM}}$ Detection System Peroxidase/DAB+kit (DAKO, Glostrup, DK) which resulted in a brown staining. A breast cancer tumor sample with known Her2 status (immunohistochemistry (IHC) 3+ and high-level amplification) and high HSP90 expression served as positive control. For negative controls, staining without the primary antibody was performed.

Her2 expression was assessed according to published recommendations for Her2 evaluation in gastric carcinoma [20], and we used the criteria for assessment of Her2 on bioptic tissue due to the tumor content of the TMA core which is comparable to a biopsy. In short, immunohistochemistry $3+$ staining was defined as strong complete basolateral or lateral membranous staining of cell clusters irrespective of the percentage of tumor cells, visible at low magnification $(\times 2.5-5)$; immunohistochemistry $2+$ was defined as weak to moderate basolateral or lateral membranous staining visible at $\times 10-20$ magnification; and immunohistochemistry $1+$ staining was defined as weak membranous staining visible only with $\times 40$ magnification. Cases without visible membranous reactivity were classified as negative (Fig. 1) All cases with Her2 score $2+$ were additionally investigated by fluorescence in situ hybridization (FISH) according to the criteria for assessment of Her2 status by the FDA/European Medicines Evaluation Agency (EMEA) for gastric cancer [20].

Expression of HSP90 (Fig. 2) was assessed by determination of cytoplasmic staining based on the intensity of immunostaining and the percentage of stained tumor cells. Immunostaining was scored as 0 (no immunostaining), 1 (weak immunostaining), 2 (moderate immunostaining), or 3 (strong immunostaining). The percentage of positive tumor cells was scored as 0 (none), $1(<10 \%), 2(10-50 \%), 3(51-$ $80 \%)$, or $4(>80 \%)$. Multiplication of the scores for intensity and percentage resulted in a staining index (SI) ranging from 0 to 12 . Similar to a previous study [19], we then divided the expression of HSP90 into low to moderate to high according to the terciles of the distribution of SI.

Evaluation of mismatch repair (MMR) genes MLH1, PMS2, MSH2, and MSH6 was performed following current recommendations [21]. Every nuclear immunoreactivity was regarded as positive. MMR deficiency was defined as a loss of expression of at least one marker. All immunohistochemical stainings were scored by two independent observers (KB, ED, or RL), and discrepancies were discussed on a multihead microscope with a final consent. Only cores with technically unequivocal staining results and sufficient tumor content $(>50$ tumor cells) were used for final analysis.

Fluorescence in situ hybridization

All cases showing an immunohistochemical Her2 score of 2+ were also tested for Her2 amplification by FISH. An assay with fluorescence-labeled locus-specific DNA probes for Her2 and chromosome-17 centromeric $\alpha$-satellite (Chrombios) was hybridized onto 4- $\mu \mathrm{m}$ TMA sections as described before [22]. FISH signal evaluation was performed 
Fig. 1 Examples of immunohistochemical stainings for Her2 in primary resected colon cancer. a Score 0 (negative). b Score $2+$. c Score $3+$ ; $\times 20$; brown membranous staining of tumor cells
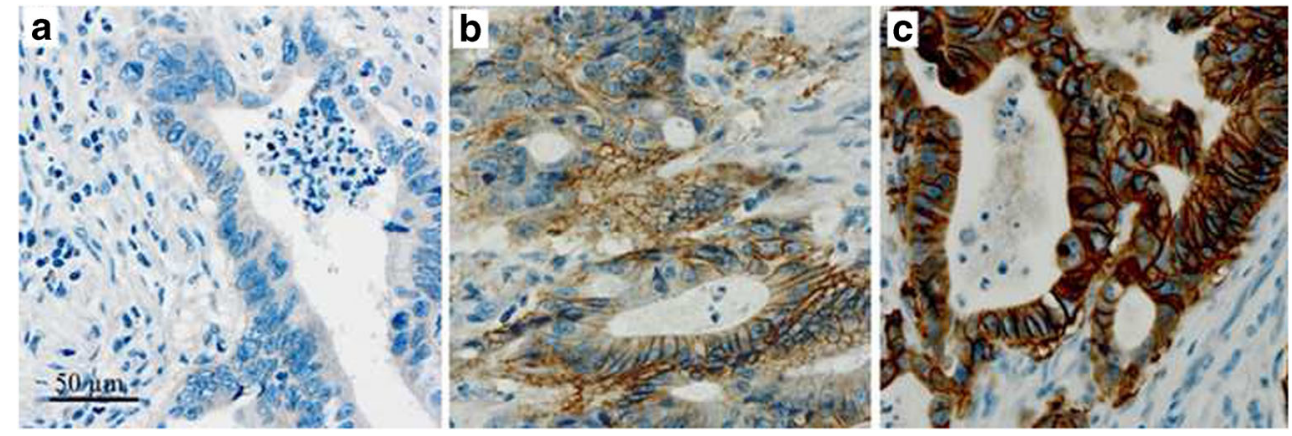

by visual counting using an epifluorescence microscope (Zeiss Axioplan 2, Carl Zeiss Microimaging $\mathrm{GmbH}$ ). At least 50 invasive tumor cells per case with a minimum of one signal for Her 2 gene and centromere 17 were randomly selected, and the mean Her 2 and centromere 17 count was calculated. Cases were classified as amplified when Her2/cep17 quotient was $\geq 2$.

\section{KRAS and BRAF analysis}

Mutational analysis of KRAS and BRAF was performed on all cases showing positive Her 2 expression (score $2+$ and $3+$ ). For this analysis, we used real-time PCR with high-resolution melting analysis (HRMA) from genomic DNA as previously described [23].

\section{Statistical analysis}

IBM SPSS 21.0 Statistics statistical software (SPSS, Inc., Chicago, IL, USA) was used for statistical analysis. Associations between immunohistochemical staining patterns, FISH analysis, and pathological features were given in crosstabs and were evaluated with $\chi^{2}$ test. Kaplan-Meier estimates, log rank tests, and Cox's proportional hazards regression analysis were used for survival analysis. All tests were two-sided, and the significance level was set at 0.05 .

\section{Results}

Patients and pathologic findings

One hundred fifty-five patients were female (44\%), and 200 of the patients were male $(56 \%)$. The mean age was $65 \pm 12$ years (median, 66; range, 25 to 91 ). Mean followup time for surviving patients was $87 \pm 27.6$ months. Complete tumor resection (R0) was achieved in 306 cases (86.2\%). All tumors were reclassified according to the current Union for International Cancer Control (UICC) TNM classification [24]. Tumor grading was done according to the WHO classifications of tumors of the digestive system [25]. The pathologic characterization of the collective is given in Table 1. The postoperative UICC staging of the tumors is given in Table 2.

Her2 expression and amplification in primary tumors

Of 355 cases, 185 tumors (52\%) showed no Her2 immunoreactivity, 119 tumors (34\%) had an immunoscore of $1+, 43$ cases $(12 \%)$ showed $2+$ immunoreactivity, and 8 cases $(2 \%)$ showed $3+$. Sixteen cases with Her2 $2+$ were found to have an amplification of Her2 using FISH. Therefore, 24 cases $(7 \%)$ would have been classified as Her2"positive status" according to the criteria of the FDA/EMEA for gastric cancer.
Fig. 2 Examples of immunohistochemical stainings for HSP90 in primary resected colon cancer. a Negative expression. b Moderate expression. c High expression; $\times 20$; brown cytoplasmic staining of tumor cells

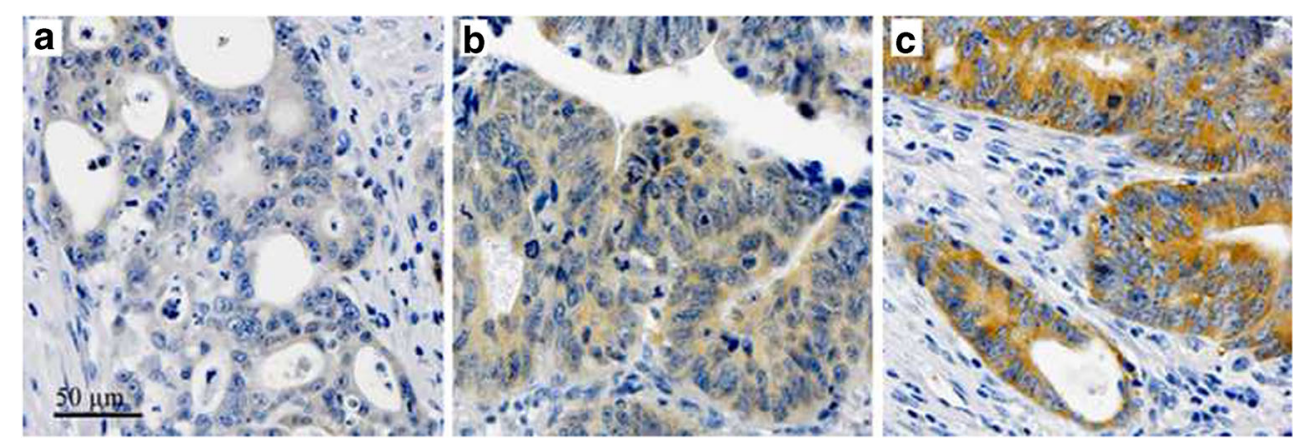


Table1 Characterization of the case collective or primary resected colon carcinomas

\begin{tabular}{ccl}
\hline Parameter & Number & Percent \\
\hline pT category & & \\
pT1 & 21 & 5.9 \\
pT2 & 62 & 17.5 \\
pT3 & 193 & 54.4 \\
pT4 & 79 & 22.3 \\
Lymph node metastases & \\
Absent & 215 & 60.6 \\
Present & 140 & 39.4 \\
Distant metastases & \\
Absent & 299 & 84.2 \\
Present & 56 & 15.8 \\
Grading & & \\
G1 & 3 & 0.8 \\
G2 & 230 & 64.8 \\
G3 & 118 & 33.2 \\
G4 & 4 & 1.1 \\
Total & & 355 \\
\hline
\end{tabular}

HSP90 expression in primary tumors

Immunohistochemical analysis for HSP90 was successfully applied on TMA cores of 353 tumors. For the remaining cases, HSP90 expression could not be studied due to too less amount of cells in the TMA cores. HSP90 expression was negative/low in 96 cases $(27 \%)$, moderate in 152 cases (43\%), and high in 105 cases (30\%).

\section{Association between Her2 and HSP90}

There was a correlation between high HSP90 expression and Her2 expression. Her2-negative tumors more frequently had

Table 2 Postoperative UICC staging of the collective of primary resected colon carcinomas

\begin{tabular}{|c|c|c|}
\hline Postoperative UICC stage & Number & Percent \\
\hline I & 74 & 20.9 \\
\hline IIA & 98 & 27.6 \\
\hline IIB & 18 & 5.1 \\
\hline IIC & 14 & 3.9 \\
\hline IIIA & 8 & 2.3 \\
\hline IIIB & 67 & 18.9 \\
\hline IIIC & 21 & 5.9 \\
\hline $\mathrm{IVA}^{\mathrm{a}}$ & 31 & 8.7 \\
\hline $\operatorname{IVB}^{\mathrm{a}}$ & 24 & 6.8 \\
\hline Total & 355 & 100.0 \\
\hline
\end{tabular}

${ }^{a}$ Forty-three patients had liver metastases (HEP), 43 patients had peritoneal metastases (PER), and 16 patients had metastases of other location; among them, eight had pulmonary metastases (PUL) low HSP90 expression levels, whereas the percentage of Her2-positive tumors with high HSP90 expression was comparable with lower HSP90 levels. This was statistically significant ( $p=0.011$; Table 3 (a)). When using the gastric cancer criteria for Her2 status, the association between HSP90 and Her2 was not statistically significant anymore. However, only 15 cases would have fallen into this group of Her2-positive cases (Table 3 (b)).

Her2 and HSP90 in lymph node metastases

Lymph node metastases of 17 cases (7 Her2-positive and 10 Her2-negative primary tumors) were additionally investigated for Her2 and HSP90. Her2 status of the primary tumors and the lymph node metastases correlated significantly with each other $(p=0.009)$, with $14 / 17$ cases $(82.3 \%)$ showing concordant results. Two cases were Her 2 positive in the primary tumor, but negative in the metastases. One case was Her2 positive in the lymph node metastasis, but negative in the primary tumor. In addition, there was a correlation between Her2 status and HSP90 expression $(p=0.035)$ also in the lymph node metastases.

Clinicopathological parameters and survival analysis

Her2 expression or amplification of the primary tumors was not associated with pT category, presence of lymph node and distant metastases, or tumor differentiation. Neither an association between Her2 and tumor localization (right sided vs. left-sided carcinomas), MMR status, or survival (Table 4, Fig. 3) was present. KRAS mutations of codon 12/13 were detected in $51 \%$ (26 cases) and BRAF mutation in $10 \%$ (5 cases) of the Her2 IHC-positive cases, which is within the range of the usual frequency of these alterations in colorectal cancer. High HSP90 expression was associated with earlier tumor stages $(p=0.019)$, absence of lymph node $(p=0.006)$,

Table 3 Correlation between (a) HSP90 expression and Her2 expression $(p=0.011)$ and (b) between HSP90 expression and Her2 status according to the FDA/EMEA $(p=0.58)$

\begin{tabular}{lllll}
\hline & \multicolumn{2}{l}{ HSP90 expression } & Total \\
\cline { 2 - 3 } & Negative & Low & High & \\
\hline (a) Her2 expression & & & & \\
Score 0/1+ & 83 & 137 & 82 & 302 \\
Score 2+/3+ & 13 & 15 & 23 & 51 \\
total & 96 & 152 & 105 & 353 \\
(b) Her2 status (FDA/EMEA) & & & \\
Negative & 86 & 145 & 98 & 329 \\
Positive & 10 & 7 & 7 & 24 \\
Total & 96 & 152 & 105 & 353 \\
\hline
\end{tabular}


Table 4 Correlation between Her2 expression and Her2 status according to the FDA/EMEA and pathological parameters

\begin{tabular}{|c|c|c|c|c|c|c|}
\hline \multirow[t]{2}{*}{ Parameter } & \multicolumn{3}{|c|}{ Her2 expression } & \multicolumn{3}{|c|}{ Her2 status (FDA/EMEA) } \\
\hline & Score $0 / 1+$ & Score $2+/ 3+$ & $p$ value & Her2 negative & Her2 positive & $p$ value \\
\hline \multicolumn{7}{|c|}{ pT category } \\
\hline pT1 & 20 & 1 & \multirow[t]{4}{*}{0.16} & 20 & 1 & \multirow[t]{4}{*}{0.54} \\
\hline pT2 & 53 & 9 & & 56 & 6 & \\
\hline pT3 & 159 & 34 & & 179 & 14 & \\
\hline pT4 & 72 & 7 & & 76 & 3 & \\
\hline \multicolumn{7}{|c|}{ Lymph node metastases } \\
\hline Absent & 260 & 39 & \multirow[t]{2}{*}{0.23} & 201 & 13 & \multirow[t]{2}{*}{0.77} \\
\hline Present & 44 & 12 & & 129 & 11 & \\
\hline \multicolumn{7}{|c|}{ Distant metastases } \\
\hline Absent & 260 & 39 & \multirow[t]{2}{*}{0.08} & 280 & 19 & \multirow[t]{2}{*}{0.32} \\
\hline Present & 44 & 12 & & 51 & 5 & \\
\hline \multicolumn{7}{|l|}{ Grading } \\
\hline 1 and 2 & 204 & 29 & \multirow[t]{2}{*}{0.32} & 218 & 15 & \multirow[t]{2}{*}{0.88} \\
\hline 3 and 4 & 100 & 22 & & 113 & 9 & \\
\hline \multicolumn{7}{|c|}{ Tumor localization } \\
\hline Right & 52 & 11 & \multirow[t]{2}{*}{0.27} & 56 & 7 & \multirow[t]{2}{*}{0.11} \\
\hline Left & 252 & 40 & & 275 & 17 & \\
\hline \multicolumn{7}{|c|}{ MMR status } \\
\hline Loss & 36 & 4 & \multirow[t]{3}{*}{0.29} & 39 & 1 & \multirow[t]{2}{*}{0.22} \\
\hline Present & 268 & 47 & & 292 & 23 & \\
\hline Total & 304 & 51 & & 331 & 24 & \\
\hline
\end{tabular}

and absence of distant metastases $(p=0.001)$, but not with tumor localization or MMR status (Table 5) Patients with high tumoral HSP90 levels had a better survival compared to those with negative or low expressing tumors ( $p=0.032$; Fig. 4 ), but

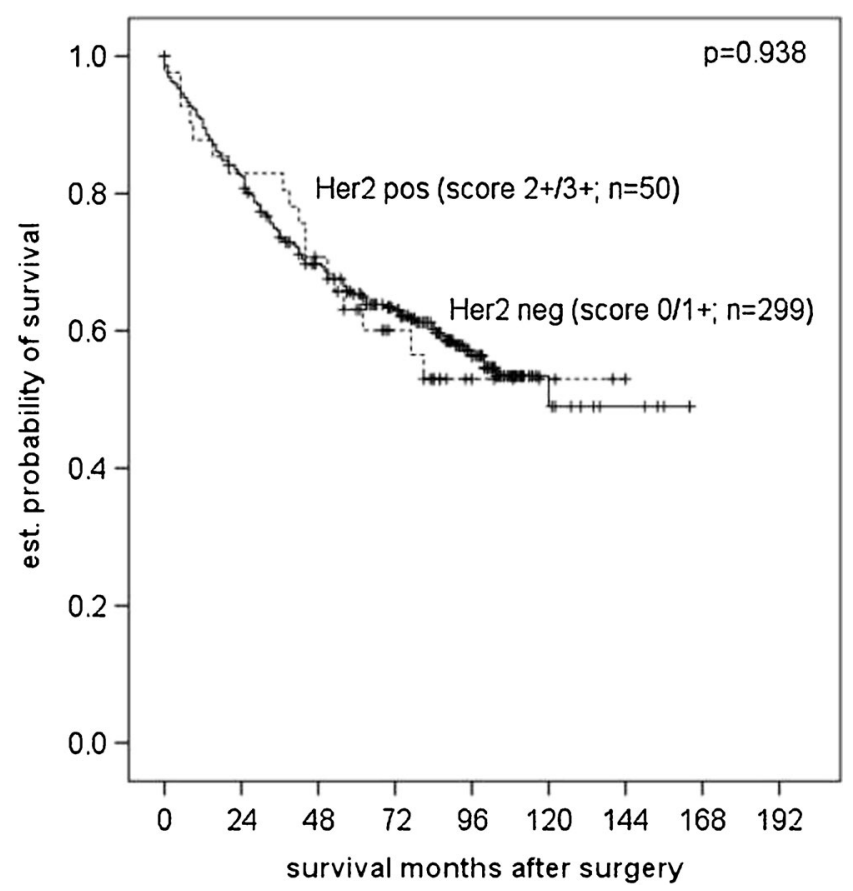

Fig. 3 No significant correlation of Her2 expression and survival in colon cancer patients this was not independent from other prognostic relevant pathologic parameters (Table 6).

\section{Discussion}

In the present study about Her2 and HSP90 in colon carcinomas, we demonstrate that elevated HSP90 expression can be observed in a significant number of cases. It is associated with lower malignant potential in these tumors. The small proportion of tumors which showed Her2 positivity significantly more frequently had also higher tumoral HSP90 expression levels.

Her2 overexpression and amplification can be observed not only in breast cancer but also in gastrointestinal tumors. Numerous studies have investigated Her2 in malignancies of the upper gastrointestinal tract, where Her2 overexpression and amplification have been detected in significant numbers of cases [1, 2]. Works on Her2 in colon and rectal carcinomas have been published to a lesser degree and report a wide range between $2 \%$ and up to over $40 \%$ Her2 positivity rates [5-12]. There is a considerable variability with regard to methodical approaches (immunohistochemistry, RT-PCR, in situ hybridization) and interpretation of, e.g., immunohistochemical staining patterns of Her2 in colorectal carcinomas which may account for these diverging data. These inconsistencies are similar to many studies on gastric cancer $[1,18]$. In order to gain better 
Table 5 Correlation between HSP90 expression and pathological parameters

\begin{tabular}{|c|c|c|c|c|}
\hline \multirow[t]{2}{*}{ Parameter } & \multicolumn{3}{|c|}{ HSP90 expression } & \multirow[t]{2}{*}{$p$ value } \\
\hline & Negative & Low & High & \\
\hline \multicolumn{5}{|c|}{ pT category } \\
\hline pT1 & 4 & 5 & 12 & \multirow[t]{4}{*}{$0.082 *$} \\
\hline pT2 & 15 & 28 & 19 & \\
\hline pT3 & 56 & 79 & 57 & \\
\hline pT4 & 21 & 40 & 17 & \\
\hline \multicolumn{5}{|c|}{ Lymph node metastases } \\
\hline Absent & 54 & 84 & 75 & \multirow[t]{2}{*}{$0.023^{* *}$} \\
\hline Present & 41 & 68 & 30 & \\
\hline \multicolumn{5}{|c|}{ Distant metastases } \\
\hline Absent & 71 & 128 & 98 & \multirow[t]{2}{*}{0.001} \\
\hline Present & 25 & 24 & 7 & \\
\hline \multicolumn{5}{|l|}{ Grading } \\
\hline 1 and 2 & 60 & 98 & 74 & \multirow[t]{2}{*}{0.46} \\
\hline 3 and 4 & 36 & 54 & 31 & \\
\hline \multicolumn{5}{|c|}{ Tumor localization } \\
\hline Right & 17 & 25 & 21 & \multirow[t]{2}{*}{0.77} \\
\hline Left & 79 & 127 & 84 & \\
\hline \multicolumn{5}{|c|}{ MMR status } \\
\hline Loss & 14 & 11 & 15 & \multirow[t]{2}{*}{0.11} \\
\hline Present & 82 & 141 & 90 & \\
\hline Total & 96 & 152 & 105 & \\
\hline
\end{tabular}

${ }^{*} p=0.019 ;{ }^{* *} p=0.006$, for high HSP90 expression vs. negative/low expression

homogenization of Her2 testing on gastric carcinomas, a proposal about standardization of immunohistochemical scoring

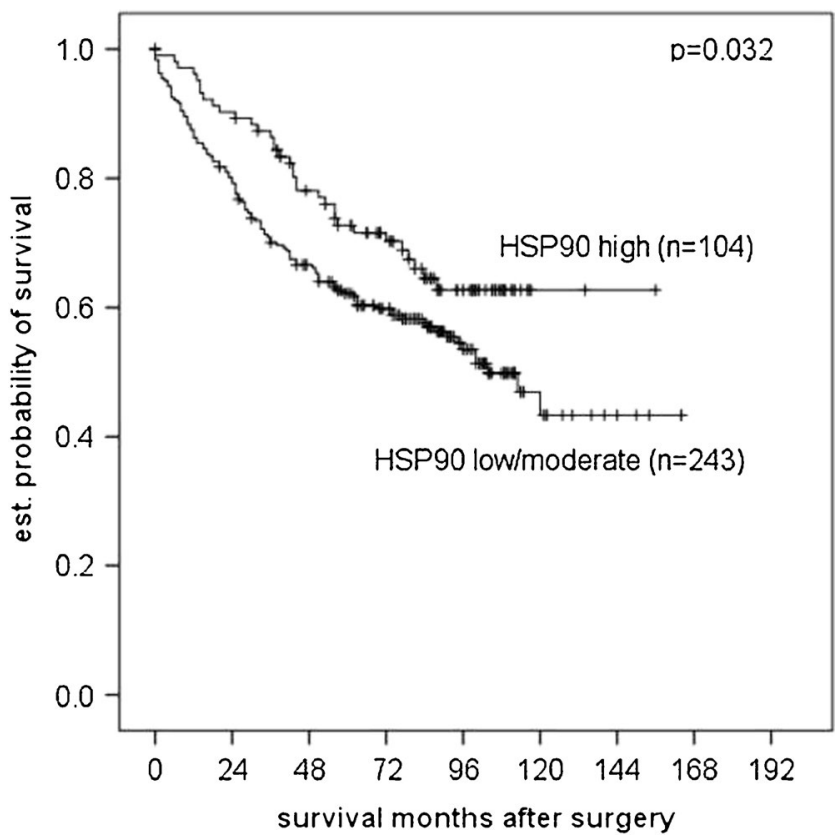

Fig. 4 Significant better survival for colon cancer patients with high tumoral HSP90 expression
Table 6 Multivariate analysis of prognostic relevant factors

\begin{tabular}{lccc}
\hline Factor & HR & $95.0 \%$ CI & $p$ value \\
\hline $\begin{array}{l}\text { pT category } \\
\text { (pT1 vs. pT2 vs. pT3 vs. pT4) }\end{array}$ & 1.472 & $1.148-1.889$ & 0.002 \\
$\begin{array}{l}\text { Lymph node metastases } \\
\text { (absent vs. present) }\end{array}$ & 1.941 & $1.356-2.777$ & $<0.001$ \\
$\begin{array}{l}\text { Distant metastases } \\
\text { (absent vs. present) }\end{array}$ & 4.927 & $3.310-7.335$ & $<0.001$ \\
$\begin{array}{l}\text { HSP90 expression } \\
\text { (negative/low vs. high) }\end{array}$ & 0.894 & $0.604-1.324$ & 0.57 \\
\hline
\end{tabular}

was recently published by the group of Rüschoff who also were responsible for the Her2 diagnostics of the TOGA study [20]. Using these criteria, we could detect elevated membranous Her2 immunoreactivity (i.e., scores $2+$ and $3+$ ) in $14 \%$ of the cases. However, if using the criteria for gastric carcinoma, where Her2 positivity is defined as either IHC $3+$ or IHC $2+$ plus positive FISH, Her2 positive status was observed in only $7 \%$.

Using this algorithm, the rate of Her2-positive tumors was recently reported to be $12 \%$ of biopsies and in up to $27 \%$ of extensively investigated resected specimens in another study on locally advanced rectal carcinomas which had been treated by neoadjuvant radiochemotherapy [26]. Our collective consisted of primary resected colon carcinomas of all stages, and we found a lower rate of Her2-positive tumors. There was no association between Her2 and relevant clinicopathologic parameters such as $\mathrm{pT}$ category, presence of lymph node and distant metastases, tumor localization, tumor differentiation, MMR status, KRAS or BRAF mutational status, or survival. Although we could not demonstrate any topographic differences when comparing right- to left-sided cancers, a sitespecific difference between colon and rectal cancer may contribute to the difference in the rate of positive cases. However, we found similar Her2 expression and amplification rates like a previous study where the breast cancer scoring system had been applied [10]. In a subset of cases, we were also able to investigate the Her2 status in lymph node metastases. Concordant to data from gastric cancer [27, 28], we found a constant Her 2 status in over $80 \%$ of the cases. Similar to the findings from gastric carcinomas, the reason for the discrepant findings in these three cases may be either a true biological phenomenon or due to a sampling bias.

We based our investigation on a tissue microarray where we have to accept a certain amount of potentially falsenegative results due to intratumoral heterogeneity, because small spots of overexpressing tumor areas may be missed in the TMA cores [29]. To take this into account, we decided to use the proposed modified criteria for Her2 testing on biopsies [20], which have comparable size and tissue content as TMA cores and which has a lower cutoff for the amount of cells whose positivity defines the Her2 status. 
Despite this limitation, TMA technology has been shown to be a powerful tool for analyzing biomarkers in larger sample collections [30]. For the purpose of an explorative study, the relatively high number of cases and the advantages of homogenous reaction conditions which avoid false-positive or false-negative staining or hybridization results because of technical reasons may equilibrate limitations regarding intratumoral heterogeneity. Our approach seems to be appropriate for the purpose of an explorative study on the association between Her2 and HSP90, which also included additional immunohistochemical analysis, such as the analysis of mismatch repair genes. For clinical practice, however, the analysis of whole tissue sections should be favored since false-negative results may generate wrong therapeutic consequences.

Elevated HSP90 expression levels could be detected in a significant number of colon carcinomas with one third of tumors showing high HSP90 expression. This was observed mainly in tumors of lower stages and also associated with a better outcome of the patients. Moreover, HSP90 expression was significantly associated with Her2 expression and amplification. The biologic activity of Her2 is influenced and controlled by molecular chaperones such as members of the group of heat shock proteins (HSPs). These molecules assist in the maintenance of cellular integrity and homeostasis by assurance of accurate folding of other proteins [13, 14]. Deregulated activity of HSPs has been found in malignant diseases which may be due to intrinsic anti-apoptotic effects but also to the altered interaction with other oncogenic molecules $[31,32]$. Recently, we could demonstrate that high tumoral expression levels of HSP27 and HSP70 are associated with negative outcome in colon cancer in the same case collection as in the present study [19]. HSP90 is one of the most abundant cellular HSPs. Besides the tyrosine kinases Her2 and EGFR, other molecules such as AKT, RAF, and RAS and mutated signaling proteins like p53 and v-Src have been described to interact with HSP90 [33, 34]. This strong association with oncogenes has evoked the interest on the impact of molecular chaperones, especially HSP90 as potential anti-tumoral targets. In vitro HSP90 inhibitors enhanced TRAIL-induced apoptosis in colorectal cancer cells via suppression of survival signaling [35]. Blocking heat shock protein 90 inhibited the growth of human colon cancer cells and improved the efficacy of oxaliplatin in p53-deficient colon cancer tumors in a mouse model [36]. On the tissue level, tumor HSP90 $\alpha$ gene overexpression has been shown to be correlated with metastases and poor prognosis in a study of 56 colorectal cancer patients [18]. This is in contrast to our findings which were obtained by immunohistochemistry and, on the protein level, generated from a much larger collective of cases. Such discrepancies between gene and protein expression data, however, are not infrequent since proteomic and genomic information often does not correlate because of different posttranslational modifications or protein turnover.
Recently, we have reported a strong correlation between HSP90 and Her2 expression in gastric carcinomas which is in line with the observations of the present study [37]. Similar observations have also been made in vitro for breast and gastric cancer, where data about overcoming Her2 resistance by increasing HSP90 activity already exist [38]. Based on these data, HSP90 may represent a potential targetable molecule, and anti-HSP90 treatment alone or in combination with other drugs may offer interesting alternative therapeutic options, especially in Her2-positive tumors [39, 40]. To the best of our knowledge, there are currently no data about the coregulation of HSP90 and Her2 in colorectal cancer yet, so that the present paper represents the first study which postulates an association between Her2 and HSP90 expression on the tissue level, in the primary tumors, and also in metastases. Although higher HSP90 levels were observed with higher frequency in the lower-stage groups, there still were a considerable number of advanced cancers showing high HSP90 as well. Since tumors of higher stages are more likely to have local or distant relapses and are therefore treated by additional cytotoxic regimes, anti-HSP90 treatment alone, or in combination with Her2 targeting could represent an additional option.

In summary, we could demonstrate an increased immunoreactivity for Her 2 and corresponding gene amplification in a small subset of colon carcinomas. High HSP90 expression levels were detected in a significant number of cases and were associated with lower malignant potential in colon cancer. The observed association between HSP90 and Her2 expression may reflect a co-regulation of these molecules. Targeting HSP90 and/or Her2 may therefore be an alternative therapeutic approach in colon cancer in a subset of patients.

Acknowledgments The authors thank Mrs. Melitta Winkler, Mrs. Ruth Wichnalek, and Mrs. Caroline Hammer for their expert technical assistance. Rupert Langer received financial support by the Deutsche Forschungsgemeinschaft (DFG), grant number LA2706/1-1.

\section{References}

1. Jorgensen JT, Hersom M (2012) HER2 as a prognostic marker in gastric cancer - a systematic analysis of data from the literature. $\mathrm{J}$ Cancer 3:137-144. doi:10.7150/jca.4090

2. Chen C, Yang JM, Hu TT, Xu TJ, Yan G, Hu SL, Wei W, Xua WP (2013) Prognostic role of human epidermal growth factor receptor in gastric cancer: a systematic review and meta-analysis. Arch Med Res. doi:10.1016/j.arcmed.2013.07.001

3. Bang YJ, Van Cutsem E, Feyereislova A, Chung HC, Shen L, Sawaki A, Lordick F, Ohtsu A, Omuro Y, Satoh T, Aprile G, Kulikov E, Hill J, Lehle M, Rüschoff J, Kang YK (2010) Trastuzumab in combination with chemotherapy versus chemotherapy alone for treatment of HER2-positive advanced gastric or gastro-oesophageal junction cancer (ToGA): a phase 3, open-label, randomised controlled trial. Lancet 376(9742):687-697. doi:10.1016/S0140-6736(10)61121-X

4. Gravalos C, Gomez-Martin C, Rivera F, Ales I, Queralt B, Marquez A, Jimenez U, Alonso V, Garcia-Carbonero R, Sastre J, Colomer R, 
Cortes-Funes H, Jimeno A (2011) Phase II study of trastuzumab and cisplatin as first-line therapy in patients with HER2-positive advanced gastric or gastroesophageal junction cancer. Clin Transl Oncol 13(3):179-184. doi:10.1007/s12094-011-0637-6

5. Marx AH, Burandt EC, Choschzick M, Simon R, Yekebas E, Kaifi JT, Mirlacher M, Atanackovic D, Bokemeyer C, Fiedler W, Terracciano L, Sauter G, Izbicki JR (2010) Heterogenous high-level HER-2 amplification in a small subset of colorectal cancers. Hum Pathol 41(11):1577-1585. doi:10.1016/j.humpath.2010.02.018

6. Baiocchi G, Lopes A, Coudry R, Rossi B, Soares F, Aguiar S, Guimarães G, Ferreira F, Nakagawa W (2009) ErbB family immunohistochemical expression in colorectal cancer patients with higher risk of recurrence after radical surgery. Int J Colorectal Dis 24(9): 1059-1068. doi:10.1007/s00384-009-0702-6

7. Li Q, Wang D, Li J, Chen P (2011) Clinicopathological and prognostic significance of HER-2/neu and VEGF expression in colon carcinomas. BMC Cancer 11(1):277

8. McKay J, Loane J, Ross V, Ameyaw M, Murray G, Cassidy J, McLeod H (2002) c-erbB-2 is not a major factor in the development of colorectal cancer. Br J Cancer 86:568-573

9. Park D, Kang M, Oh S, Kim H, Cho Y, Sohn C, Jeon W, Kim B, Han W, Kim H, Ryu S, Sepulveda A (2007) HER-2/neu overexpression is an independent prognostic factor in colorectal cancer. Int J Colorectal Dis 22:491-497

10. Kavanagh D, Chambers G, O'Grady L, Barry K, Waldron R, Bennani F, Eustace P, Tobbia I (2009) Is overexpression of HER-2 a predictor of prognosis in colorectal cancer? BMC Cancer 9:1-6

11. Schuell B, Gruenberger T, Scheithauer W, Zielinski C, Wrba F (2006) Her-2/neu protein expression in colorectal cancer. BMC Cancer 6: 123

12. Herreros-Villanueva M, Rodrigo M, Claver M, Muñiz P, Lastra E, García-Girón C, Coma del Corral M (2011) KRAS, BRAF, EGFR and HER2 gene status in a Spanish population of colorectal cancer. Mol Biol Rep 38(2):1315-1320. doi:10.1007/s11033-010-0232-x

13. Sidera K, Gaitanou M, Stellas D, Matsas R, Patsavoudi E (2008) A critical role for HSP90 in cancer cell invasion involves interaction with the extracellular domain of HER-2. J Biol Chem 283(4):20312041. doi:10.1074/jbc.M701803200

14. Citri A, Harari D, Shohat G, Ramakrishnan P, Gan J, Lavi S, Eisenstein M, Kimchi A, Wallach D, Pietrokovski S, Yarden Y (2006) Hsp90 recognizes a common surface on client kinases. J Biol Chem 281(20):14361-14369. doi:10.1074/jbc.M512613200

15. Lang SA, Klein D, Moser C, Gaumann A, Glockzin G, Dahlke MH, Dietmaier W, Bolder U, Schlitt HJ, Geissler EK, Stoeltzing O (2007) Inhibition of heat shock protein 90 impairs epidermal growth factormediated signaling in gastric cancer cells and reduces tumor growth and vascularization in vivo. Mol Cancer Ther 6(3):1123-1132. doi: 10.1158/1535-7163.MCT-06-0628

16. Neckers L, Workman P (2012) Hsp90 molecular chaperone inhibitors: are we there yet? Clin Cancer Res 18(1):64-76. doi:10.1158/ 1078-0432.ccr-11-1000

17. Kubota $H$, Yamamoto S, Itoh E, Abe Y, Nakamura A, Izumi Y, Okada H, Iida M, Nanjo H, Itoh H, Yamamoto Y (2010) Increased expression of co-chaperone HOP with HSP90 and HSC70 and complex formation in human colonic carcinoma. Cell Stress Chaperon 15(6): 1003-1011. doi:10.1007/s12192-010-0211-0

18. Chen W-S, Lee C-C, Hsu Y-M, Chen C-C, Huang T-S (2011) Identification of heat shock protein $90 \alpha$ as an IMH-2 epitopeassociated protein and correlation of its mRNA overexpression with colorectal cancer metastasis and poor prognosis. Int J Colorectal Dis 26(8):1009-1017. doi:10.1007/s00384-011-1200-1

19. Bauer K, Nitsche U, Slotta-Huspenina J, Drecoll E, von Weyhern $\mathrm{CH}$, Rosenberg R, Hofler H, Langer R (2012) High HSP27 and HSP70 expression levels are independent adverse prognostic factors in primary resected colon cancer. Cell Oncol (Dordr) 35(3):197-205. doi:10.1007/s13402-012-0079-3
20. Rüschoff J, Hanna W, Bilous M, Hofmann M, Osamura RY, PenaultLlorca F, van de Vijver M, Viale G (2012) HER2 testing in gastric cancer: a practical approach. Mod Pathol 25(5):637-650. doi:10. 1038/modpathol.2011.198

21. Müller A, Giuffre G, Edmonston TB, Mathiak M, Roggendorf B, Heinmöller E, Brodegger T, Tuccari G, Mangold E, Buettner R, Rüschoff J (2004) Challenges and pitfalls in HNPCC screening by microsatellite analysis and immunohistochemistry. J Molec Diagn 6(4):308-315. doi:10.1016/S1525-1578(10)60526-0

22. Rauser S, Weis R, Braselmann H, Feith M, Stein HJ, Langer R, Hutzler P, Hausmann M, Lassmann S, Siewert JR, Hofler H, Werner M, Walch A (2007) Significance of HER2 low-level copy gain in Barrett's cancer: implications for fluorescence in situ hybridization testing in tissues. Clin Cancer Res 13(17):5115-5123. doi:10. 1158/1078-0432.CCR-07-0465

23. Bettstetter M, Berezowska S, Keller G, Walch A, Feuchtinger A, Slotta-Huspenina J, Feith M, Drecoll E, Hofler H, Langer R (2012) Epidermal growth factor receptor, phosphatidylinositol-3-kinase catalytic subunit/PTEN, and KRAS/NRAS/BRAF in primary resected esophageal adenocarcinomas: loss of PTEN is associated with worse clinical outcome. Hum Pathol. doi:10.1016/j.humpath.2012.08.005

24. Sobin L, Gospodarowicz ML, Wittekind C (2010) TNM classification of malignant tumors. Wiley, New York

25. Bosman FT, Carneiro F, Hruban RH, Theise ND (eds) (2010) WHO classification of tumours of the digestive system, 4th edn. Lyon, World Health Organization

26. Conradi LC, Styczen H, Sprenger T, Wolff HA, Rodel C, Nietert M, Homayounfar K, Gaedcke J, Kitz J, Talaulicar R, Becker H, Ghadimi M, Middel P, Beissbarth T, Rüschoff J, Liersch T (2013) Frequency of HER-2 positivity in rectal cancer and prognosis. Am J Surg Pathol 37(4):522-531. doi:10.1097/PAS.0b013e318272ff4d

27. Bozzetti C, Negri FV, Lagrasta CA, Crafa P, Bassano C, Tamagnini I, Gardini G, Nizzoli R, Leonardi F, Gasparro D, Camisa R, Capelli S, Silini EM, Ardizzoni A (2011) Comparison of HER2 status in primary and paired metastatic sites of gastric carcinoma. Br J Cancer 104(9):1372-1376

28. Kochi M, Fujii M, Masuda S, Kanamori N, Mihara Y, Funada T, Tamegai H, Watanabe M, Suda H, Takayama T (2013) Differing deregulation of HER2 in primary gastric cancer and synchronous related metastatic lymph nodes. Diagn Pathol 8(1):191. doi:10.1186/ 1746-1596-8-191

29. Warneke VS, Behrens HM, Boger C, Becker T, Lordick F, Ebert MP, Rocken C (2012) Her2/neu testing in gastric cancer: evaluating the risk of sampling errors. Ann Oncol. doi:10.1093/annonc/mds528

30. Ilyas M, Grabsch H, Ellis IO, Womack C, Brown R, Berney D, Fennell D, Salto-Tellez M, Jenkins M, Landberg G, Byers R, Treanor D, Harrison D, Green AR, Ball G, Hamilton P (2013) Guidelines and considerations for conducting experiments using tissue microarrays. Histopathol 62(6):827-839. doi:10.1111/his.12118

31. Calderwood SK, Khaleque MA, Sawyer DB, Ciocca DR (2006) Heat shock proteins in cancer: chaperones of tumorigenesis. Trends Biochem Sci 31(3):164-172

32. Ciocca DR, Calderwood SK (2005) Heat shock proteins in cancer: diagnostic, prognostic, predictive, and treatment implications. Cell Stress Chaperones 10(2):86-103

33. Porter JR, Fritz CC, Depew KM (2010) Discovery and development of Hsp90 inhibitors: a promising pathway for cancer therapy. Curr Opin Chem Biol 14(3):412-420. doi:10.1016/j.cbpa.2010.03.019

34. Hong DS, Banerji U, Tavana B, George GC, Aaron J, Kurzrock R (2013) Targeting the molecular chaperone heat shock protein 90 (HSP90): lessons learned and future directions. Cancer Treat Rev 39(4):375-387. doi:10.1016/j.ctrv.2012.10.001

35. Saturno G, Valenti M, De Haven BA, Thomas GV, Eccles S, Clarke PA, Workman P (2013) Combining trail with PI3 kinase or HSP90 inhibitors enhances apoptosis in colorectal cancer cells via suppression of survival signaling. Oncotarget 4(8):1185-1198 
36. Moser C, Lang SA, Kainz S, Gaumann A, Fichtner-Feigl S, Koehl GE, Schlitt HJ, Geissler EK, Stoeltzing O (2007) Blocking heat shock protein-90 inhibits the invasive properties and hepatic growth of human colon cancer cells and improves the efficacy of oxaliplatin in p53-deficient colon cancer tumors in vivo. Mol Cancer Ther 6(11): 2868-2878. doi:10.1158/1535-7163.mct-07-0410

37. Berezowska S, Novotny A, Bauer K, Feuchtinger A, SlottaHuspenina J, Becker K, Langer R, Walch A (2013) Association between HSP90 and Her2 in gastric and gastroesophageal carcinomas. PLoS One 8(7):e69098. doi:10.1371/journal.pone. 0069098

38. Ono N, Yamazaki T, Nakanishi Y, Fujii T, Sakata K, Tachibana Y, Suda A, Hada K, Miura T, Sato S, Saitoh R, Nakano K, Tsukuda T,
Mio T, Ishii N, Kondoh O, Aoki Y (2012) Preclinical antitumor activity of the novel heat shock protein 90 inhibitor CH5164840 against human epidermal growth factor receptor 2 (HER2)-overexpressing cancers. Cancer Sci 103(2):342-349. doi:10.1111/j.13497006.2011.02144.x

39. Patel HJ, Modi S, Chiosis G, Taldone T (2011) Advances in the discovery and development of heat-shock protein 90 inhibitors for cancer treatment. Expert Opin Drug Discov 6(5):559-587. doi:10. 1517/17460441.2011.563296

40. Jhaveri K, Taldone T, Modi S, Chiosis G (2012) Advances in the clinical development of heat shock protein 90 (Hsp90) inhibitors in cancers. Biochim Biophys Acta 1823(3):742-755. doi:10.1016/j. bbamcr.2011.10.008 